\title{
An Alternative Method of the Direct Closure for the Radial Forearm Flap Donor-Site Defect: Lazy S Double-Opposing Rotation Flaps
}

\author{
Atsumori Hamahata, MD, PhD ${ }^{1}$ Takeshi Beppu, MD, PhD ${ }^{2}$ Atsuyoshi Osada, MD \\ Takashi Yamaki, MD, $\mathrm{PhD}^{3}$ Hiroyuki Sakurai, MD, $\mathrm{PhD}^{3}$
}

${ }^{1}$ Division of Plastic and Reconstructive Surgery, Saitama Cancer Center, Saitama, Japan

2 Division of Head and Neck Surgery, Saitama Cancer Center, Saitama, Japan

${ }^{3}$ Department of Plastic and Reconstructive Surgery, Tokyo Women's Medical University, Tokyo, Japan

J Reconstr Microsurg Open 2016;1:63-66.

The free radial forearm flap remains a workhorse flap for head and neck reconstruction, although perforator flap or super microsurgery has become increasingly popular. Yet donorsite morbidities, including unsightly appearances that may occur when sites are closed via skin graft, cause reconstructive surgeons to be hesitant to use the forearm flap. Elliot et al (1988) reported the direct closure method for donor-site defects of the radial forearm flap using the V-Y flap, and several modifications have been reported based on their methods. ${ }^{1-8}$ However, partial skin necrosis sometimes occurs along the lateral side of the flap even though the perforators from ulnar artery are preserved well, and this necrosis leaves ugly wide scarring on patients' forearms (-Fig. 1). To minimize these drawbacks, simple lazy S double-opposing rotation flaps were designed for the donor site of the radial forearm flap, and the donor-site defect was closed directly. In this report, the details of the method and the outcomes are described.

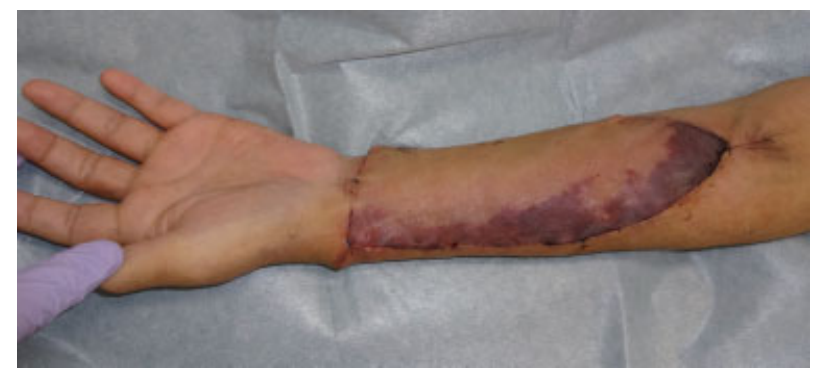

Fig. 1 Partial skin necrosis along the lateral side of the flap in V-Y flap closure.

received

November 17, 2015

accepted after revision

February 4, 2016

published online

March 22, 2016
Address for correspondence Atsumori Hamahata, MD, PhD, Division of Plastic and Reconstructive Surgery, Saitama Cancer Center, 780 Komuro Inamachi Kitaadachigunn Saitama, Saitama, Japan (e-mail: a.hamahata@cancer-c.pref.saitama.jp).

\section{Materials and Methods}

From March 2010 to April 2015, 17 patients in the Saitama Cancer Center (Saitama, Japan) had free radial forearm flaps harvested and closed to the donor site directly. Six patients were closed using the V-Y flap as Elliot et al (1988) reported, and 11 patients were closed using the lazy $S$ double-opposing rotation flaps (the following surgical procedure). The size of the harvested radial forearm flap and the rate of marginal necrosis on the donor site 1 week after the operation were studied retrospectively. Statistical comparison was performed by Fisher exact test. The statistical calculation was performed using the Prism software (GraphPad Software Inc., San Diego, CA).

\section{Surgical Procedure (Lazy S Double-Opposing Rotation Flaps)}

In the method of the lazy $\mathrm{S}$ double-opposing rotation, first, the radial artery line was marked on the patient's forearm and a point approximately $6.0 \mathrm{~cm}$ from the wrist line was also marked on the radial artery line. Then, a lazy S line that passed through the marked point was designed on the patient's forearm and the radial forearm flap was designed along the line of the lazy $S$ at the point's center (-Figs. $\mathbf{2 A}$ and $\mathbf{3 A}$ ). The radial forearm flap was elevated under avascularization with a tourniquet. After the proximal rotation flap was elevated, the radial artery and vein were exposed and the radial forearm flap was harvested as usual. When closing the donor site, the distal rotation flap was elevated and the distal and proximal rotation flaps were moved to the defect of the donor site (-Fig. 2B). Using both the flaps, the donor-site defect of the radial forearm flap was completely covered and the rotation flaps' donor site was closed using

Copyright $\odot 2016$ by Thieme Medical Publishers, Inc., 333 Seventh Avenue, New York, NY 10001, USA.

License terms 10.1055/s-0036-1580607. ISSN 2377-0813. 


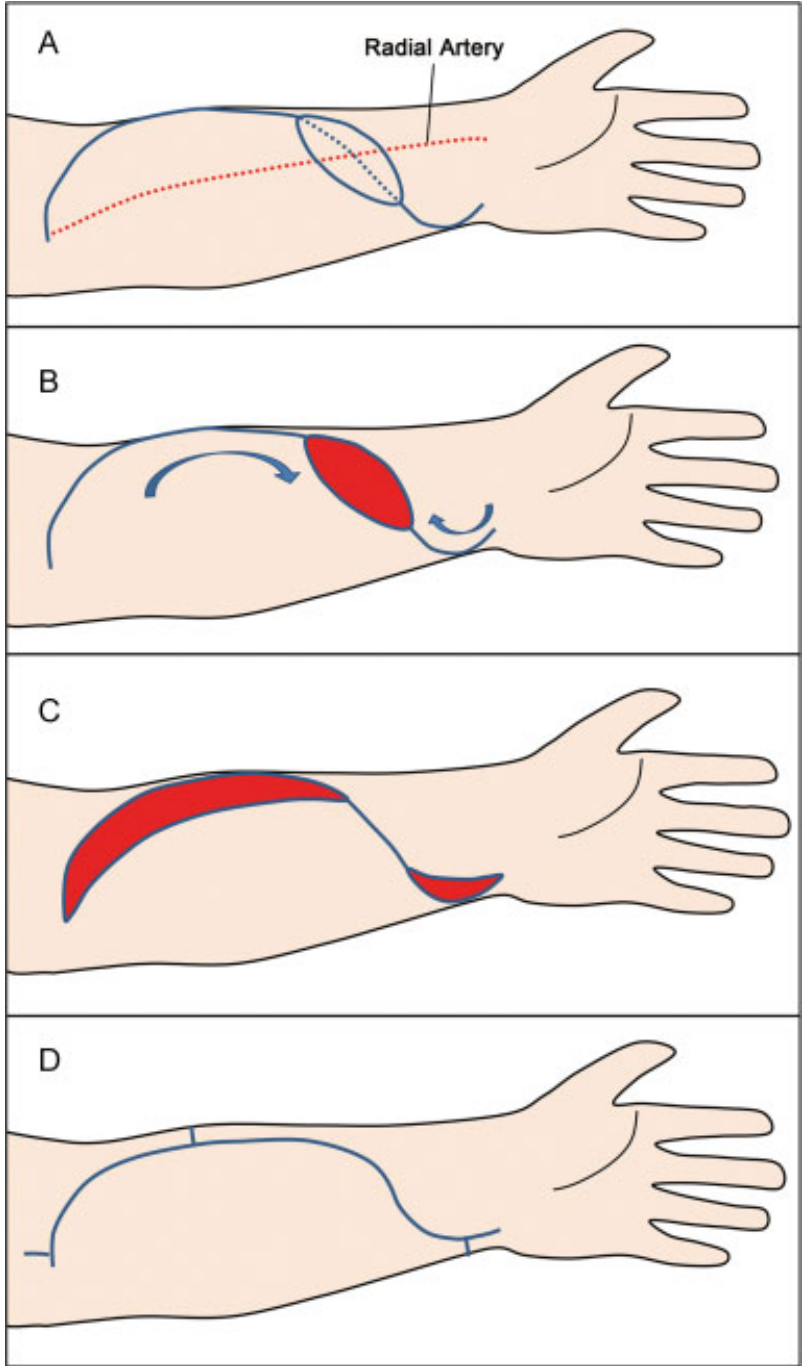

Fig. 2 Schema of the lazy $S$ double-opposing rotation flap closure. The lazy $S$ line passes through the marked point ( $6.0 \mathrm{~cm}$ from the wrist line) and the radial forearm flap is designed along the line of the lazy $S$ at the center of the point (A). The distal and proximal rotation flaps are moved to the defect of the donor site (B and C). The rotation flaps' donor site is closed using surrounding skin with several Burow triangles (D).

surrounding skin with several Burow triangles (-Fig. 2C, D). Wrist fixation using a splint was performed for 5 to 7 days to reduce skin tension in the forearm.

\section{Results}

- Table 1 summarizes the size of the harvested radial forearm flap and the rate of marginal necrosis on the donor site of patients in the $\mathrm{V}-Y$ group and lazy $\mathrm{S}$ double rotation group. In the V-Y group, average flap size was $6.1 \mathrm{~cm}$ length and $4.0 \mathrm{~cm}$ width and maximum flap size was $7.0 \mathrm{~cm}$ length and $4.0 \mathrm{~cm}$ width. In the lazy $S$ double rotation group, average flap size was $7.1 \mathrm{~cm}$ length and $4.0 \mathrm{~cm}$ width and maximum flap size was $8.0 \mathrm{~cm}$ length and $4.5 \mathrm{~cm}$ width. Four of the six patients had more than $1 \mathrm{~cm}$ width marginal necrosis in the lateral side of the V-Y flap, and two patients had less than $1 \mathrm{~cm}$ width marginal necrosis in the V-Y flap group, although wounds were cured using conservative therapy within a month. Meanwhile, none of the 11
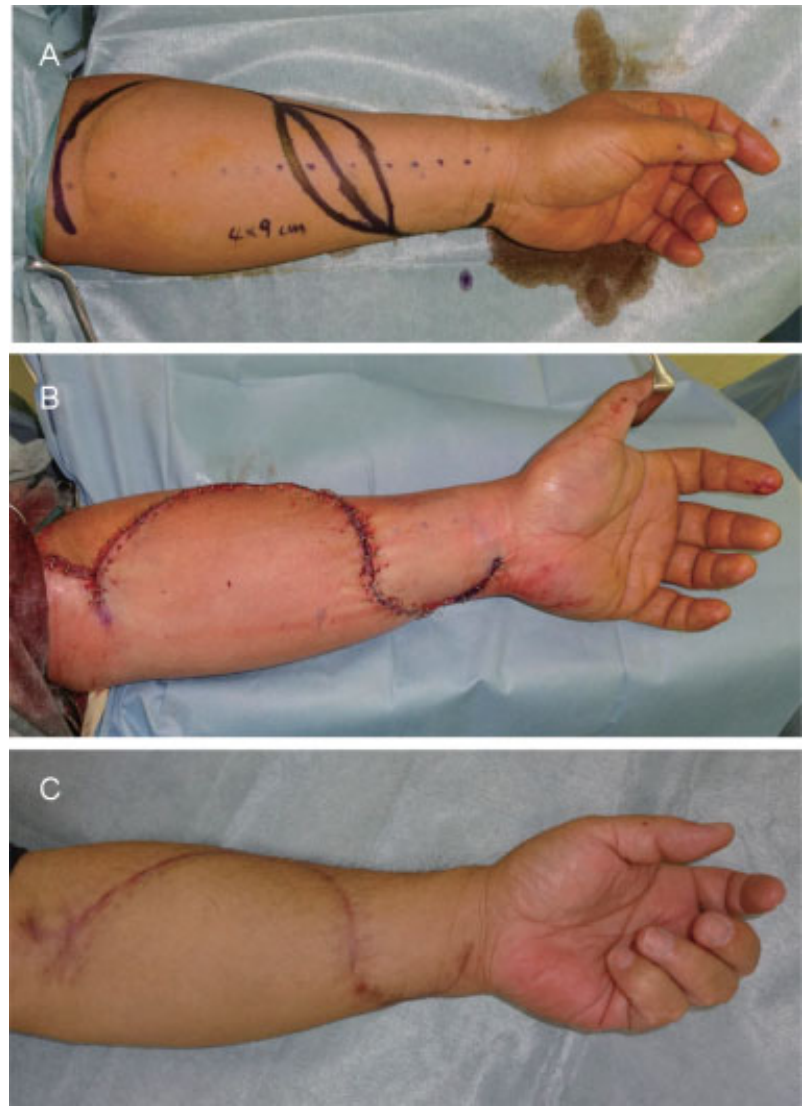

Fig. 3 A representative case: The design of the radial forearm flap $(9.0 \times 4.0 \mathrm{~cm})$ and the lazy $S$ double-opposing rotation flaps $(A)$, after closure of the donor site (B), and view of the donor site after 6 months (C).

patients had more than $1 \mathrm{~cm}$ width marginal necrosis and only 3 patients had less than $1 \mathrm{~cm}$ width marginal necrosis in the lazy $S$ double rotation group. There were significant differences between the V-Y group and lazy $S$ double rotation group relative to more than $1 \mathrm{~cm}$ width marginal necrosis rate $(p=0.0014)$ and total necrosis rate $(p=0.009)$.

\section{Discussion}

Several methods have been reported to close the radial forearm flap donor site directly. ${ }^{2-8}$ In such methods, the V-Y advancement flap has been mainly used for the direct closing of the radial forearm flaps donor site because of its simple design. ${ }^{1}$ Other modifications have good results, but the methods are too complicated just for closing the donor site. Nonetheless, the V-Y advancement flap is simple and practical, but the forearm skin may become necrotic even though perforators from the ulnar artery are preserved well, causing forearm scarring to be conspicuous. To overcome these drawbacks, we developed a new simple design to close the donor site after forearm flap harvest.

The double-opposing rotation flap can be used by both sides of the skin defect effectively in areas where surrounding skin is limited. To adapt the flaps to the forearm, a lazy S is designed first, followed by a forearm flap design along the lazy S line. By designing the double-opposing rotation flaps 
Table 1 Size of the harvested radial forearm flap and the rate of marginal necrosis on the donor site of patients in the $\mathrm{V}-\mathrm{Y}$ group and lazy S double rotation group

\begin{tabular}{|c|c|c|c|c|c|c|c|}
\hline Patient & Age $(y)$ & Sex & Original cancer & Comorbidity & $\begin{array}{l}\text { Flap } \\
\text { size }(\mathrm{cm})\end{array}$ & $\begin{array}{l}\text { Marginal necrosis } \\
\text { (more than } 1 \mathrm{~cm} \text { ) }\end{array}$ & $\begin{array}{l}\text { Marginal necrosis } \\
\text { (less than } 1 \mathrm{~cm} \text { ) }\end{array}$ \\
\hline \multicolumn{8}{|c|}{ V-Y group } \\
\hline 1 & 59 & M & Hypopharyngeal carcinoma & - & $5.5 \times 4$ & - & Yes \\
\hline 2 & 65 & M & Carcinoma of oral floor & - & $6 \times 4$ & Yes & \\
\hline 3 & 46 & M & Lingual carcinoma & - & $7 \times 4$ & Yes & - \\
\hline 4 & 74 & $\mathrm{~F}$ & Carcinoma of buccal mucosa & HT & $6 \times 4$ & Yes & - \\
\hline 5 & 63 & M & Carcinoma of oral floor & & $6 \times 4$ & - & Yes \\
\hline 6 & 73 & M & Pharyngocutaneous fistula & HT & $6 \times 4$ & Yes & - \\
\hline \multicolumn{8}{|c|}{ Lazy S double-rotation group } \\
\hline 1 & 40 & $\mathrm{~F}$ & Lingual carcinoma & - & $5.5 \times 3.5$ & - & - \\
\hline 2 & 67 & M & Carcinoma of oral floor & HT & $7 \times 4$ & - & - \\
\hline 3 & 46 & $\mathrm{M}$ & Carcinoma of buccal mucosa & - & $6 \times 4$ & - & - \\
\hline 4 & 64 & M & Lingual carcinoma & HT & $7 \times 4$ & - & - \\
\hline 5 & 75 & $\mathrm{M}$ & Carcinoma of oral floor & $\mathrm{DM}$ & $6 \times 4$ & - & Yes \\
\hline 6 & 48 & $\mathrm{M}$ & Lingual carcinoma & - & $8 \times 4.5$ & - & - \\
\hline 7 & 64 & $\mathrm{M}$ & Lingual carcinoma & - & $8 \times 4$ & - & - \\
\hline 8 & 63 & $\mathrm{M}$ & Lingual carcinoma & - & $8 \times 4$ & - & Yes \\
\hline 9 & 60 & $\mathrm{~F}$ & Hypopharyngeal carcinoma & - & $6 \times 4$ & - & - \\
\hline 10 & 52 & $\mathrm{M}$ & Lingual carcinoma & - & $9 \times 4$ & - & - \\
\hline 11 & 80 & $\mathrm{M}$ & Lingual carcinoma & HT & $8 \times 4.5$ & & Yes \\
\hline
\end{tabular}

Abbreviations: DM, diabetes mellitus; F, female; $\mathrm{HT}$, hypertension, $\mathrm{M}$, male.

along the lazy S line, circulation of the double-opposing rotation flaps is better maintained because the base of the rotation flap remains wider. In our study, none of the 11 patients had more than $1 \mathrm{~cm}$ width marginal necrosis and only 3 patients had less than $1 \mathrm{~cm}$ width marginal necrosis in the lazy $S$ double rotation group. The pedicle length of the radial forearm flap is shorter in the lazy $S$ double rotation group by approximately 3 to $4 \mathrm{~cm}$ compared with the $\mathrm{V}-\mathrm{Y}$ flap group, but a longer pedicle is rarely used for head and neck reconstruction if the operation is not a salvage one. Thus, the pedicle length of the radial forearm flap was sufficient for all patients in the lazy $S$ double rotation group. In the lazy $S$ double rotation group, average flap size was $7.1 \mathrm{~cm}$ length and $4.0 \mathrm{~cm}$ width and maximum flap size was $8.0 \mathrm{~cm}$ length and $4.5 \mathrm{~cm}$ width. When using radial forearm flap for head and neck reconstruction, this average-sized flap is mostly used for medium defects such as hemiglossectomy, oral floor carcinoma resection, and buccal mucosal carcinoma resection, although a larger-sized flap that required for skin graft is used in some cases.

\section{Conclusion}

The lazy S double-opposing rotation flaps provides better appearance outcomes and stable skin circulation in the forearm, and could prove to be one of the most useful methods for closing the donor site of radial forearm flap directly, although size limitations do exist.

Conflict of Interest

None.

\section{Acknowledgment}

The authors would like to thank Jeffrey D. Meserve for his editorial assistance.

\section{References}

1 Elliot D, Bardsley AF, Batchelor AG, Soutar DS. Direct closure of the radial forearm flap donor defect. Br J Plast Surg 1988;41(4): 358-360

2 Bardsley AF, Soutar DS, Elliot D, Batchelor AG. Reducing morbidity in the radial forearm flap donor site. Plast Reconstr Surg 1990; 86(2):287-292, discussion 293-294

3 Shoaib T, Van Niekerk WJ, Morley S, Ellabban MA, Soutar DS. The ulnar artery perforator based islanded V-Y flap closure of the radial forearm flap donor site. J Plast Reconstr Aesthet Surg 2009; 62(3):421-423 
4 Avery CM, Pereira J, Brown AE. Suprafascial dissection of the radial forearm flap and donor site morbidity. Int J Oral Maxillofac Surg 2001;30(1):37-41

5 Hsieh CH, Kuo YR, Yao SF, Liang CC, Jeng SF. Primary closure of radial forearm flap donor defects with a bilobed flap based on the fasciocutaneous perforator of the ulnar artery. Plast Reconstr Surg 2004;113(5):1355-1360
6 Yii NW, Niranjan NS. Fascial flaps based on perforators for reconstruction of defects in the distal forearm. Br J Plast Surg 1999;52(7):534-540

7 Masser MR. The preexpanded radial free flap. Plast Reconstr Surg 1990;86(2):295-301, discussion 302-303

8 van Kampen RJ, Corten EM, Schellekens PP. The split radial forearm flap for lower leg defects. Ann Plast Surg 2014;73(5):535-539 